\title{
$¿$ Caben las medidas cautelares constitucionales en contra de un proceso arbitral?
}

Juan Francisco Guerrero del Pozo 1

\section{Sumario}

1. Las medidas cautelares constitucionales en el régimen jurídico ecuatoriano. 2. El caso Wesco Vs. Banco de Guayaquil. 3. ¿Caben medidas cautelares constitucionales para suspender un proceso arbitral? 4. Corolario.

\section{LAS MEDidAS CAUTELARES CONSTITUCIONALES EN EL RÉGIMEN JURÍDICO ECUATORIANO}

Es importante empezar por realizar algunas consideraciones respecto de las medidas cautelares constitucionales. Es común escuchar que la acción de amparo constitucional vigente hasta la promulgación de la actual Constitución fue reemplazada por la acción de protección. Sin embargo, aquello no es preciso, puesto que la acción de amparo constitucional, al menos en su faceta cautelar, fue sustituida por la acción de medidas cautelares constitucionales que constituyen un mecanismo transitorio para evitar la violación o cesar la violación de un derecho constitucional.

1. Profesor de Derecho Constitucional y Derecho Procesal de la Facultad de Jurisprudencia de la Pontificia Universidad Catölica del Ecuador y de la Universidaư Andina Simón Bolivar. 
De conformidad con lo que establece el artículo 87 de la Constitución y artículo 26 y siguientes de la L. Orgánica de Garantías Jurisdiccionales y Control Constitucional (LOGJCC), para que proceda una medida cautelar es indispensable que concurran los siguientes elementos.

a) Que exista la amenaza inminente de violación de un derecho constitucional o una violación continua de un derecho constitucional, de tal manera que con la medida cautelar se puede evitar la violación o hacer cesar la violación del derecho. Si la violación al derecho ya se ha consumado y ha agotado, la medida cautelar no es procedente y la reparación del daño causado debería perseguirse a través de una acción de protección u otra garantía jurisdiccional dependiendo del derecho vulnerado.

b) Que el daño que se cause sea grave, gravedad que se determina en función de la intensidad o frecuencia de la amenaza o violación del derecho. La L. Orgánica de Garantías Jurisdiccionales y Control Constitucional, a mi modo de ver restrictivamente y por ende inconstitucionalmente ${ }^{2}$, ha agregado el hecho de que ese daño debe ser irreversible ${ }^{3}$.

En cuanto a las características de las medidas cautelares, siguiendo a ROBERTO VILLARREAL ${ }^{4}$, debemos mencionar tres características básicas: la instrumentalidad, la provisionalidad y la revocabilidad.

En cuanto a la instrumentalidad, es decir, el que no constituyan un fin en sí mismas, sino que están subordinadas a una

2. El articulo 11 numeral 4 de la Constitución establece que "Ninguna notma juridica podrá restringir el conterido de los derechos ni de las garantias constitucionales".

3. Sin lugar a dudas que resulta cuestionable el que en la LOGJCC se hable de que para que proceda una medida cautelar frente a la amenaza inminente y grave de violar un derecho, la gravedad esté supeditada a que el daño causado sea irreversible, ya que la mera violación de un derecho constitucional reviste una alta gravedad que merece ser evilada y por ende el pretender que el daño sea además irre. versibie constituye una condición inconstitucional $\mathrm{c}$ improcedente.

4. Villarkent, Roberto. Medidas Cautclares, Quito: Cevallos Editora Juridica, 2010, p. 358. 
resolución definitiva. Cabe señalar que si bien la Constitución y la LOGJCC establecen que las medidas cautelares pueden presentarse conjunta o independientemente de las otras garantías jurisdiccionales, aquello no implica que las medidas cautelares constitucionales dejen de estar subordinadas a una acción principal, aunque esta no necesariamente debe ser constitucional5. Lo dicho se evidencia claramente en el artículo 28 de la LOGJCC que establece que la resolución del juez respecto de las medidas solicitadas no implicará un prejuzgamiento sobre la declaración de violación de un derecho, lo cual implica que existe una cuestión de fondo que debe ventilarse y respecto de la cual las medidas cautelares solicitadas no serán vinculantes o determinantes.

En cuanto a la provisionalidad, es necesario señalar que como toda medida cautelar, las medidas cautelares constitucionales no pueden ser indefinidas, sino que conforme lo establece el artículo 33 de la LOGJCC, debe establecerse las circunstancias de tiempo en que deben cumplirse, lo que se traduce en que cuando se adopta una medida de esta naturaleza, el juez debe determinar con absoluta precisión cuál es el límite temporal de la medida. Esta característica puede clarificarse con un caso hipotético: si cualquier autoridad emite un acto administrativo, que por la presunción de legitimidad y ejecutoriedad está llamado a ejecutarse inmediatamente a pesar de que pueda ser cuestionado a través de un recurso subjetivo o de plena jurisdicción ante la Jurisdicción Contencioso Administrativa ${ }^{6}$, si yo considero que vulnera derechos constitucionales puedo solicitar la suspensión de su ejecución a través de una medida cautelar constitucional, pero esta suspensión no la puedo solicitar, y sobre todo la juez o el juez no la puede conceder de forma indefinida, sino que debe estar sujeta a la resolución que sobre la cuestión de fondo debe emitir el Tribunal Contencioso Administrativo. De

5. Por ejemplo podria dictarse una medida cautelar constitucional que suspenda la cjecución de un acto administrativo micntras se sustancia la vía contencioso administrativa.

6. El inciso primero del anícula $76 \mathrm{de} \mathrm{la} \mathrm{L}$. de la Jurisdicción Contencioso Administrativa establece que "Saivo lo dispucsto en el articulo precedente, en ningún caso se suspenderá la ejecueión o cumpli. miento del acto administrativo." 
esta manera se respetarán las características de provisionalidad e instrumentalidad de las medidas cautelares constitucionales.

La característica de revocabilidad implica que las medidas cautelares constitucionales pueden ser revocadas en cualquier momento cuando se demuestre que ya se ha evitado o cesado la violación del derecho, hayan cesado los requisitos establecidos en la Constitución y la ley o se demuestre que carecían de fundamento ${ }^{7}$. En todo caso, las decisiones que se adopten a partir de la concesión de una medida cautelar constitucional no generarán efectos de cosa juzgada y la posibilidad de solicitar su revocatoria no caducará ni prescribirá, por lo que podrá solicitarse en cualquier momento e inclusive en más de una ocasión, siempre que la medida ya se haya ejecutado.

Por otra parte, es necesario tener presente que el inciso tercero del artículo 27 de la LOGJCC establece que no procederán las medidas cautelares cuando:

a) Existan medidas cautelares en las vías administrativas $u$ ordinarias;

b) Cuando se trate de ejecución de órdenes judiciales; y,

c) Cuando se interpongan en la acción extraordinaria de protección 8 .

\section{El caso Wesco Vs. Banco de Guayaquil}

En el caso concreto del arbitraje, en el Ecuador existe un caso que ha generado debate y preocupación respecto de la aplicabi-

7. Cfr. articulo 35 de la L. Orgánica de Garantias Jurisdiccionales y Control Constitucional.

8. No se alcanza a entender el por qué el legislador incorporó la improcedencia de las medidas cautelares constitucionales cuando se trata de una acción extraordinaria de protección, ya que a más de implicar una restricción inconstitucional de una garantia jurisdiccional, acarrıa en la práctica serios inconvenientes, ya que impide que la Corte Constitucional, al conocer una demanda de acción extraordinaria de protección pueda suspender la cjecución de la decisión cuestionada, lo que se traduce en que en caso de que deternine, lucgo del procedimicnto correspondiente, que efectivamente la decisión jurisdiccional violenta derechos fundamentales, se dificulte y cn cicrtos casos incluso se imposibilite la reparación integral del daño causado en los términos del articulo 86 numeral 3 de la Constitución. 
lidad de las medidas constitucionales. Por cuanto todas las piezas procesales a las que me referiré se encuentran incorporadas a procesos públicos de libre acceso en la función judicial, me permitiré inclusive hacer referencia a las partes involucradas.

La compañía Pinturas Wesco C.A. presentó una demanda en contra del Banco de Guayaquil S.A. ante un Juez de lo Civil de Pichincha alegando que la institución financiera le había infringido daños y perjuicios que debían ser reparados a través de la indemnización correspondiente. Luego de más de tres años de litigio', el Juez de lo Civil de Pichincha a quien le correspondió el conocimiento de la causa, aceptó la alegación de incompetencia formulada por el Banco de Guayaquil, declaró la nulidad de todo lo actuado por considerar que existía entre las partes un convenio arbitral, y de conformidad con el artículo 129 numeral 9 del Código Orgánico de la Función Judicial, ordenó que el proceso sea remitido al "Tribunal Arbitral de la Cámara de Comercio de Quito".

Una vez que el juzgado envió el proceso formado al Centro de Arbitraje y Mediación de la CCQ el Presidente del Centro emitió una providencia en la cual requirió a Pinturas Wesco la presentación de la demanda en los términos del artículo 10 de la LAM a fin de darle el trámite correspondiente. Efectivamente Pinturas Wesco presentó la demanda arbitral, la cual fue calificada y posteriormente citada al Banco de Guayaquil, quien dentro del término concedido, dio contestación a la demanda ${ }^{10}$. Siguiendo el trámite correspondiente ${ }^{11}$, el Presidente del Centro de Arbitraje y Mediación, convocó a la correspondiente audiencia de mediación a fin de que las partes procuren llegar a un acuerdo respecto de sus diferencias.

9. Es sorprendente el que el proceso se haya sustanciado durante más de tres años, cuando de haberse alegado la existencia de convenio arbitral por parte del demandado, lo procedente era sustanciar el incidente de conformidad con lo que estabiece el artículo 8 de la LAM.

10. Cfr. articulo II L.AM.

11. Cfr. articulo 15 LAM. 
Frente a la providencia en la que se convocaba a la audiencia de mediación, el Banco de Guayaquil acudió ante un juez de instancia de la provincia del Guayas y propuso una petición de medidas cautelares en contra de dicha providencia y solicitó la suspensión del proceso arbitral iniciado, alegando que se encontraban en peligro los siguientes derechos constitucionales del Banco:

- El derecho al debido proceso y a la tutela judicial efectiva.

- El derecho a ser demandado en el lugar del domicilio (la Constitución no contempla este Derecho, sino el derecho a ser juzgado por un juez competente, imparcial e independiente ${ }^{12}$ )

- El derecho a la libertad de contratación, alegando que el Banco de Guayaquil no ha contratado los servicios del Centro de Arbitraje y Mediación de la CCQ.

- El derecho al honor y buen nombre del Banco de Guayaquil.

Frente a dicho pedido, el juez de instancia de la provincia del Guayas, resolvió conceder la medida cautelar solicitada, sustentada en que "existe una amenaza o violación de los derechos constitucionales del accionante, esto es, del Banco de Guayaquil, al obligárselo a comparecer y defenderse en el juicio arbitral No. 75-2010 sin existir cláusula arbitral expresa que prevea dicho proceso arbitral". Es importante reparar en que el juez ordenó la suspensión del proceso arbitral:

a) Sin determinar si se encontraba frente a un caso de amenaza de violación o violación de un derecho constitucional;

b) Sin establecer cuáles eran los derechos cuya violación era inminente o cuya violación era continua y por ende debía cesar;

12. Cfr. articulo 76, numeral 7, literal k) de la Constitución. 
c) Pronunciándose anticipadamente sobre la incompetencia del Tribunal Arbitral desconociendo lo expresamente establecido en el artículo 22 de la LAM en cuanto a que es el Tribunal Arbitral quien resolverá sobre su propia competencia (KOMPETENZ SUR KOMPETENZ);

d) Sin respetar la provisionalidad de la medida cautelar, es decir, la ordenó de forma indefinida; $y$,

e) Sin respetar la instrumentalidad de la medida, al no establecer a qué pronunciamiento de fondo estará subordinada.

Ante la medida cautelar dictada, el Director del Centro de Arbitraje y Mediación de la CCQ, solicitó su revocatoria, alegando primordialmente que el Centro de Arbitraje y Mediación de la CCQ había actuado en estricto apego a la providencia del juez de lo civil de Pichincha que se encontraba ejecutoriada y que por ende no cabían medidas cautelares en contra de dicha decisión, por cuanto el artículo 27 de la LOGJCC establece que no caben medidas cautelares cuando se trata de ejecución de órdenes judiciales. Frente a dicho pedido de revocatoria, el juez de instancia de la provincia del Guayas se limitó a señalar que por no tener constancia física de la existencia de un convenio arbitral, desechaba el pedido de revocatoria y mantuvo la medida vigente.

\section{3. ¿CABEN MEDIDAS CAUTELARES PARA SUSPENDER UN PROCESO ARBITRAL?}

A partir del caso relatado se generan algunas cuestiones respecto de la procedencia o no de las medidas cautelares para suspender un proceso arbitral, las cuales merecen un análisis minucioso:

1. Las medidas cautelares ordenadas no cumplían con la característica de provisionalidad e instrumentalidad, puesto que la suspensión ordenada era indefinida y no estaba 
subordinada a ningún pronunciamiento de fondo, lo cual de por sí implicaba la desnaturalización de la medida. La indefinición temporal de la medida acarrea además una violación de los derechos constitucionales del accionante, ya que si la justicia ordinaria había remitido la causa a un centro arbitral y la sustanciación del arbitraje hubiera es suspendida indefinidamente, nos encontramos frente a un caso de denegación de justicia y por ende de violación del derecho a la tutela judicial efectiva. Es más, en el supuesto que Pinturas Wesco decidiera iniciar un proceso en la ciudad de Guayaquil, ¿no podría acaso alegarse la excepción de Litis Pendencia por parte del Banco de Guayaquil, ya que la suspensión del proceso no implica su terminación?

2. Según la forma de funcionamiento del Tribunal, el arbitraje puede ser independiente (ad-hoc) o administrado (institucional), siendo el primero aquel en el que "no existe ninguna institución que administre el sistema, ni está sometido a ningín mecanismo predeterminado. Sont las propias partes quienes deberán ponerse de acuerdo en las reglas sobre las cuales se desarrollará el arbitraje"13, mientras que el administrado (institucional) es aquel en que "una entidad especializada que administra y organiza el trámite, y presta sus servicios sumamente útiles para que la contienda pueda ser resueltn con mayor eficacia" 14 .

En nuestro país, ambas modalidades de arbitraje se encuentran reconocidas expresamente en el artículo 2 de la LAM.

No existe en la actualidad duda de que los procedimientos arbitrales son procedimientos jurisdiccionales incluso constitucionalmente reconocidos ${ }^{15}$, lo cual a su vez se

13. Villakenl, Roque J. Arbitrajc. Bucnos Aires: AD-HOC, 2000, p. 70.

14. Ibid, p. 67.

15. Cfr. articulo $190 \mathrm{de} \mathrm{la} \mathrm{Constitución}$ 
traduce en que las actuaciones que el árbitro o árbitros realizan dentro del procedimiento, son actuaciones de índole jurisdiccional y por ende, al amparo de lo que establece el artículo 27 de la LOGJCC no procede dictar medidas cautelares en su contra. Sin embargo, la duda surge en el arbitraje administrado (institucional) respecto de lo que en la doctrina se denomina etapa o trámite prearbitral que va desde la presentación de la demanda arbitral, hasta que el Director del Centro de Arbitraje pone a disposición de los árbitros el expediente formado cuando procede a posesionar al Tribunal. Precisamente en el caso anotado, es un acto dictado dentro de la etapa prearbitral el que es objeto de la medida cautelar constitucional.

Si bien es interesante la alegación del Centro de Arbitraje y Mediación de la CCQ en cuanto a que las providencias cuestionadas han sido dictadas en ejecución de una decisión judicial y que por ende no cabe la interposición de medidas cautelares en contra de la ejecución de decisiones judiciales, esta posición implícitamente deja abierta la posibilidad de que cuando no exista una decisión judicial previa que declare que un determinado conflicto debe resolverse por la vía arbitral, si cabría medidas cautelares constitucionales, lo cual sin lugar a dudas resulta bastante cuestionable y debilita al arbitraje en el país.

Corresponde entonces, analizar cuál es la naturaleza de los actos del Director de un Centro de Arbitraje, claro está, cuando hablamos de un arbitraje institucional o administrado como lo denomina nuestra ley.

$\mathrm{Al}$ respecto debemos tener presente cuáles son las atribuciones que de conformidad con la LAM le corresponden al Director del Centro de Arbitraje: 
- Recibir la demanda (artículo 10)

- Calificar la demanda y disponer la citación al demandado (artículo 11)

- Recibir la contestación a la demanda (artículo 11)

- Calificar la reconvención y correr traslado al actor para que la conteste (artículo 12)

- Correr traslado a las partes para que contesten la modificación de la demanda, su contestación, la reconvención o la contestación a esta última (artículo 13)

- Convocar a las partes a audiencia de mediación y designar mediador (artículo 15)

- Convocar a los árbitros designados para que tomen posesión de sus cargos ante el Presidente del Centro de Arbitraje (artículo 17)

- Resolver sobre la recusación de un árbitro cuando los no recusados del tribunal no se pusieren de acuerdo sobre la recusación planteada (artículo 21 literal a)

- En caso de que la recusación recayere sobre todos los árbitros, resolver sobre ella (artículo 21 literal b)

Existe una posición doctrinaria que considera que el Director del Centro ejerce funciones administrativas, de auxilio, apoyo o simplemente preparatorias o introductorias para la etapa arbitral.

Otra posición sostiene que las actuaciones y funciones del Director del Centro de arbitraje son jurisdiccionales.

Ahora bien, respecto al tema que nos ocupa en este momento, esta discusión resulta especialmente relevante, puesto que si aceptamos el carácter jurisdiccional de las actuaciones del Director del Centro, aquello nos llevará a concluir que no es posible suspender un proceso arbitral a través de medidas cautelares constitucionales y tampoco serán susceptibles de ser cuestionadas sus actuaciones a través de una acción de protección. Si por 
el contrario, consideramos que las actuaciones del Director del Centro no son jurisdiccionales, abriríamos la puerta para que, al menos en principio, sean cuestionables a través de garantías jurisdiccionales, claro está, si se reúnen los demás requisitos que han quedado enunciados, esto es, que se amenace de forma inminente con violar un derecho constitucional.

Un primer argumento a favor de que los actos del Director del Centro de Arbitraje son de índole jurisdiccional, radica en que en los arbitrajes independientes esas mismas atribuciones son ejercidas por él o los árbitros, $\sin$ que exista discusión alguna en cuanto a que dichas actuaciones se las realiza en ejercicio de facultades de índole jurisdiccional, razón por la cual no se comprendería el por qué la naturaleza de esos mismos actos mutaría cuando se trate de un arbitraje administrado.

Un segundo argumento que debe considerarse a favor de la tesis de que los actos del Director del Centro de Arbitraje son jurisdiccionales, es que al tratarse de procesos ordinarios, son actuaciones que le corresponden al juez y que inclusive se encuentran expresamente reguladas en nuestro Código de Procedimiento Civil, como por ejemplo, la calificación de la demanda, la convocatoria a una diligencia conciliatoria, la citación con la demanda, y ni qué decir del pronunciamiento respecto a una recusación.

Sobre este tema resulta pertinente lo dicho por la Corte Constitucional Colombiana en la sentencia C-1038 expedida el 28 de noviembre de 2002, en la cual al respecto concluyó que: "Conforme a lo anterior, la Corte Concluye que la fase prearbitral tiene una naturaleza jurisdiccional, por las siguientes razones: i) puede implicar limitaciones al acceso a la administración de justicia; ii) está destinada a impulsar el proceso arbitral, que es de 
naturaleza arbitral, y iii) en su fondo y forma está sometida a lo previsto en el estatuto procesal civil para los procesos judiciales."

Todas estas razones le son plenamente aplicables a la denominada fase "prearbitral" en el Ecuador, razón por la cual puede afirmarse que las actuaciones del Director del Centro de Arbitraje son jurisdiccionales. No obstante lo indicado, debe anotarse que en ese mismo fallo, a partir de la determinación del carácter jurisdiccional de las actuaciones en la fase "prearbitral", la Corte Constitucional Colombiana declaró la inconstitucionalidad de las normas que atribuían tales competencias al Director del Centro de Arbitraje y determinó que todas esas competencias deben ejercerse por parte del tribunal arbitral después de su instalación.

$\mathrm{Al}$ respecto, es necesario tener presente que el inciso final del artículo 116 de la Constitución Colombiana dispone que: "Los particulares pueden ser investidos transitoriamente de la función de administrar justicia en la condición de conciliadores o en la de árbitros habilitados por las partes para proferir fallos en derecho o en equidad, en los términos que determine la ley."

Esta norma, según el criterio de la Corte Constitucional Colombiana, en virtud del principio de habilitación, le inhabilita al legislador a atribuir funciones jurisdiccionales a los Centros de Arbitraje y a su Director, por lo que declaró la inconstitucionalidad parcial de la norma que atribuía estas funciones al Director de los Centros de Arbitraje.

En el Ecuador el artículo 190 de la Constitución es bastante más general y establece: "Se reconoce el arbitraje, la mediación y otros métodos alternativos para la solución de conflictos. Estos procedimientos se aplicarán con suje- 
ción a la ley, en materias que por su naturaleza se pueda transigir $(\ldots)^{\prime \prime}$

Por lo tanto, no sería aplicable el principio de habilitación, puesto que el margen que el constituyente le otorgó al legislador ecuatoriano es mucho más amplio que el que se le otorgó al colombiano, por lo que en el Ecuador no habría, al menos desde el punto de vista constitucional, incompatibilidad para que el Director del Centro de Arbitraje ejerza actos jurisdiccionales, sin perjuicio de que en una eventual reforma a la LAM se analice la posibilidad de que todas estas actuaciones sean ejercidas directamente por el árbitro o tribunal arbitral una vez que se haya posesionado.

\section{Corolario}

En el Ecuador no debería ser posible a través de medidas cautelares constitucionales, suspender la sustanciación de un procedimiento arbitral, ya que a más de generar una violación del derecho constitucional a la tutela judicial efectiva, las actuaciones arbitrales son de naturaleza jurisdiccional que por disposición expresa de la ley no están sujetas a dichas medidas. Sin embargo, debe reflexionarse respecto a las atribuciones que la LAM les otorga a los Directores de los Centros de Arbitraje en los arbitrajes administrados, ya que al tratarse de atribuciones jurisdiccionales, estas deberían ser ejercidas directamente por los tribunales arbitrales, claro está, con la necesaria asistencia y auxilio de los Centros de Arbitraje. 